\title{
Congenital Icthyosis: A case report
}

\author{
Rajesh Pandey* \\ Division of Neonatal-Perinatal Medicine, University of Texas Health Science Center at Houston, Houston, TX 77030, USA
}

\begin{abstract}
Congenital Ichyosis is relatively uncommon disease but is the most common cause of Collodian baby. Early diagnosis is required for immediate management and prevention of fluid-electrolyte balance as well as prevention of secondary infections. Definitive diagnosis is essential for long-term management as well as counselling to the parents of affected infant if they are considering having children together.
\end{abstract}

\section{Case report}

A full term male infant was born by spontaneous vaginal delivery to a $35 \mathrm{y} / \mathrm{o}, \mathrm{G} 5 \mathrm{P} 4$ woman. Her prenatal course, including prenatal ultrasound, was unremarkable.

Examination at birth: He had normal anthropometry with height, weight and head circumference being between $25^{\text {th }}$ to $75^{\text {th }}$ percentiles.

Skin: Diffuse erythematous skin lesion with collodion membrane covering the chest and back, tight skin on upper and lower extremities, fissures on areas with skin folds, eversion of the eyelids with inability for complete eye examination, eversion of the lips, and malformation of the auricle.

Tone and turgor: with in normal limit.

Heent: Anterior fontanelle: soft and flat, normal shape and size.

Eyes: Eversion of the eyelids.

Ears: External malformation, unable to assess if secondary to skin lesions.

Nose: Nares and septum appear with in normal limit.

His cardiovascular, abdominal, spine, back, extremities and external gentile examinations were normal.

On further evaluation, family history was not significant for any medical and dermatological conditions. There was no history of consanguinity. The patient has a 2 y/o healthy full sister. Mother was carrier for Cystic Fibrosis. He has two half-brothers (13 y/o and 10 y/o) from maternal side who has eczema, otherwise healthy; two half-sisters and one brother from paternal side- all reportedly healthy (Figure 1 and 2).

\section{Discussion}

Collodion baby is a severe form of Congenital Icthyosis. Congenital Icthyosis is heterogeneous group of disorders of cornification involving all or most of integumentary system [1] which is characterized by a generalized scaling of the skin of varying severity. Mucosal surface and visceral organs are generally spared. Cornification is process of terminal keratinocyte differentiation. At this stage, a lipid envelope is extruded into the intercellular space from lamellar bodies to form lipid sheets composed of ceramides, cholesterol, and free fatty acids [2].

\section{Normal skin turnover}

Skin has dermis and epidermis layers. Epidermis has four layersstratum basale, spinosum, granulosum, and corneum from base to top. During normal skin turnover of 28 days, site-relevant proteins and lipids are synthesized in different layers of epidermis.

\section{Revised nomenclature and classification of inherited ichthyoses}

The First Ichthyosis Consensus Conference in Sorèze 2009 proposed the following pathogenesis of inherited Icthyosis [1] which is based on disorders involved in different stages of protein and lipid metabolism and on other mechanism.

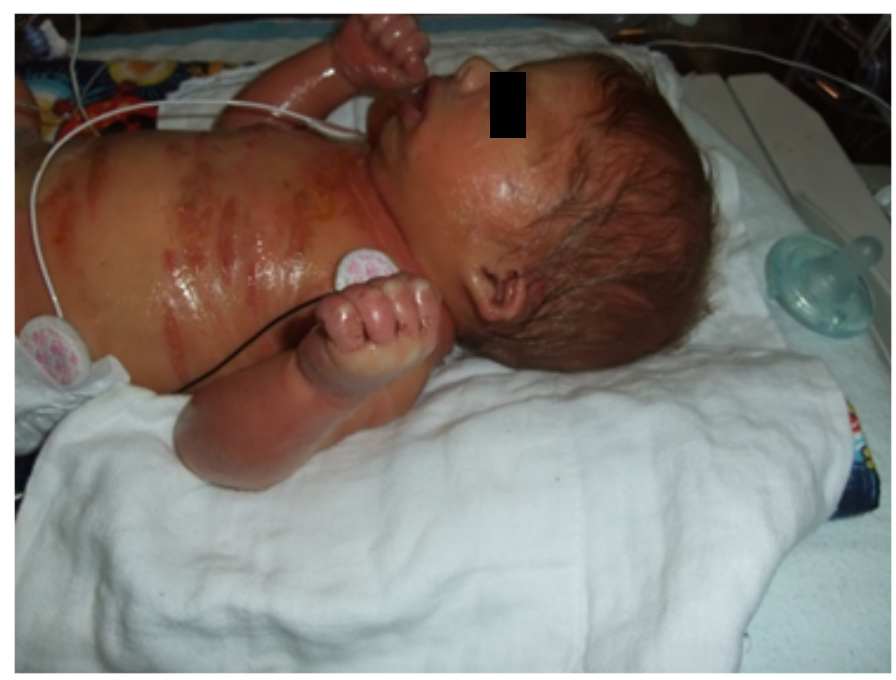

Figure 1. Collodion membrane with eclabion, tight membrane around joints.

Correspondence to: Rajesh Pandey, Assistant Professor of Pediatrics, Division of Neonatal-Perinatal Medicine, University of Texas Health Science Center at Houston, 6431 Fannin St, Suite 3.218, Houston, TX 77030, USA, Tel: (713) 500 6364; Fax: (713) 500-5727; Email: Rajesh.Pandey@uth.tmc.edu

Received: January 04, 2017; Accepted: January 23, 2017; Published: January 26, 2017 


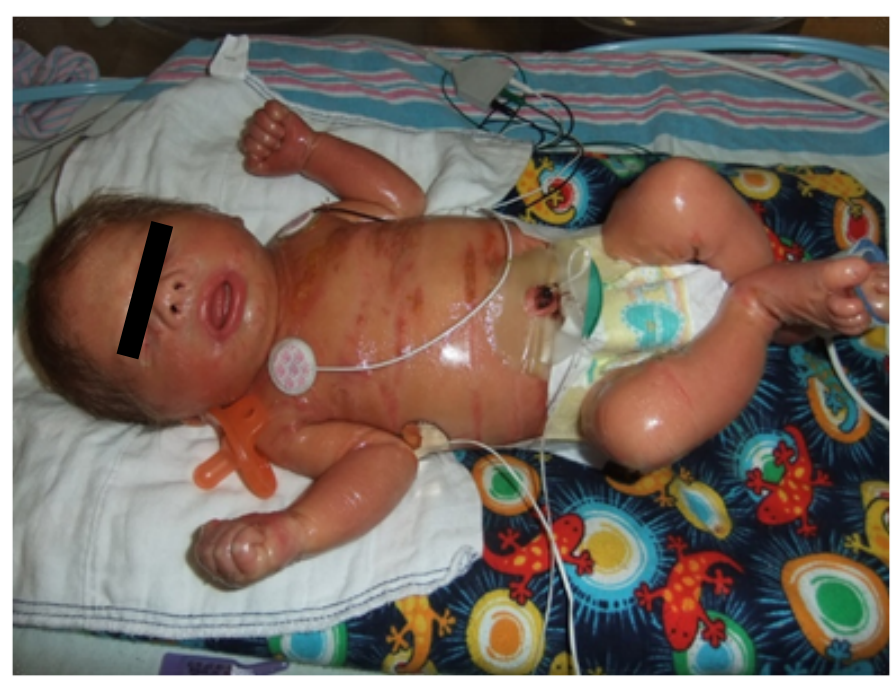

Figure 2. Collodion membrane with eclabion and ectropion.

Table 1. Clinico-genetic classification of inherited Icthyosis. Abbreviations: ARCI, autosomal recessive congenital ichthyosis; CNS, central nervous system; KI, keratinopathic ichthyoses; IV Icthyosis Vulgaris; RXLI Recessive X Linked Icthyosis; HI Harelquin Icthyosis; LI Lamellar Icthyosis; CIE: congenital Icthyosiform erythroderma; EI epiodermolytic icthyosis; SEI superficial epidermolytic icthyosis [1].

\section{Non-syndromic ichthyoses}

1. Common ichthyoses: IV, RXLI

2. ARCI: HI, LI, CIE

3. KI: EI, SEI

4. Other forms of non-syndromic ichthyosis

Syndromic ichthyoses

5. X-linked ichthyosis syndromes

6. Other ichthyosis syndromes (CNS signs, fatal disease course, hair abnormalities and/ or other associated signs)

(A) Disorders of keratinocyte protein ("bricks") metabolismcytoskeleton, cornified lipid- cell envelope, protease/protease inhibitors, that lead to weakening of cytoskeleton and decreased mechanical stability/cytotoxic effects, premature loss and defective processing).

(B) Disorders of lipid ("mortar") metabolism- defective assembly or transport of lipids including steroid sulfatase deficiency, lipid metabolism defects including liposomal and neutral lipid storage diseases.

(C) Disorders of tight and gap junctions and

(D) Disorders of DNA transcription/ repair.

Same consensus nomenclature classified inherited Icthyosis as following (Table 1):

\section{Clinical features}

Collodion baby (CB) is a presentation of inherited Icthyosis-it is not a disease. It is called "inherited" to different from rare condition of "acquired Icthyosis", primarily seen adults as a manifestation of systemic disease, including paraneoplastic syndrome. Collodion membrane is transient, transparent membrane present at birth, made of keratinized epithelium [3]. Clinical course of collodion baby varies widely with complete resolution within few weeks in ten percent, lifelong complication of various degrees to most affected individuals and five percent mortality as neonate [4]. Skin peeling occurs from weeks to months of life [5].

$\mathrm{CB}$ presents at birth with erythroderma and shiny, tight skin resembling parchment (the so-called collodion membrane) covering the entire body [4]. The mechanical force of membrane causes distortion in different body parts that can result ectropion, eclabion, pseudocontractures, absence of eyebrows, sparse hair, and hypoplasia of nasal and auricular cartilage [4]. Distal limb ischemia and hypohydrosis has been reported. Less common presentation includes poor sucking (due to eclabion), restricted pulmonary ventilation (decreased chest wall compliance), digital vascular constriction, and edema of the extremities [6]. After birth, the expansion of the chest with breathing may cause tearing in the inelastic membrane, which begins to peel. The membrane is shed within 3 to 4 weeks, usually revealing an ichthyosis phenotype $[4,6]$. CB is rare, estimated to occur in 1 in 50,000 to 100,000 deliveries. Most CB infants are born at full-term and are appropriate size for gestational age. A slight male predominance has been found in the literature [4] and this is explained by the fact that only males are affected by $\mathrm{X}$ linked forms of inherited ichthyosis. Cases have been reported in twins, and consanguinity of parents has been noted [7]. Vitamin D deficiency rickets has been reported to be associated with Icthyosis [8].

\section{Newborn management}

Fluid and electrolyte management: Increased insensible water loss, more than five times normal trans-epithelial water loss has been reported, which leads to dehydration and hypernatremia $[9,10]$. To avoid dehydration, newborn are kept in isolette with high humidity and milk/ intravenous fluid intake is adjusted to avoid dehydration. $\mathrm{CB}$ also have impaired sweating mechanism so clinical must be vigilant to avoid and aggressively treat hyperthermia and hypohydrosis. Daily weight and electrolytes help in maintaining fluid and electrolyte balance.

Routine use of emollients is controversial as it helps decreasing insensible water loss but increases the risk of infection [11,12]. Defecting skin barrier promotes bacterial and fungal infection. Deep skin crease may delay early diagnosis. Daily skin examination including skin fissures is recommended. Rigorous hand wash cannot be over emphasized. Early diagnosis and aggressive treatment of both local and systemic infection is required for better outcome. Eye care should be coordinated with ophthalmologist and bland lubricant is recommended to prevent development of keratitis and conjunctivitis $[6,13]$. For severe scaling, oral retinoids, such as acitretin and isotretinoin, are an important therapeutic option [14].

\section{Our case}

We kept newborn in tertiary level NICU. He was in Isolette with humidity of 70-80\%. He was given feeds in demand and IV fluid for first 2 days. Intravenous Ampicillin and gentamycin was given for 5 days. We monitored daily weight and electrolytes, strict input and output. There was no significant weight change and no electrolyte abnormalities. We used topical Vaseline twice daily and looked for signs and symptoms of cutaneous and systemic infections daily. $\mathrm{He}$ did not have any infection. He got eye lubricants 3-4 times a day to prevent dry eye and its complications. Baby had umbilical venous line for first five days of life, as it was almost impossible to get peripheral IV access. We sent genetic testing for TMG1 gene. There was significant improvement in skin by early $2^{\text {nd }}$ week of life- erythema decreased and collodion membrane shed. Skin was almost normal looking by end of 2 
weeks. Ectropion of eyelid and eclabion improved as membrane shed. Genetic testing were negative. He got afebrile, superficial skin infection, treated with systemic antibiotics at 6 weeks of age. Child is doing well in 15 months of life. We discussed the inheritance of congenital Icthyosis. The majority of cases of congenital Icthyosis are inherited in an autosomal recessive manner. This means that for both male and female offspring, the risk of recurrence is $25 \%$ with each pregnancy.

\section{References}

1. Oji V, Tadini G, Akiyama M, Bardon C, Bodemer C, et al. (2009) Revised nomenclature and classification of inherited ichthyoses: Results of the First Ichthyosis Consensus Conference in Sorèze 2009. J Am Acad Dermatol 63: 607-641.

2. Nemes Z, Steinert PM (1999) Bricks and mortar of the epidermal barrier. Exp Mol Med 31: 5-19.[Crossref]

3. O'Toole Kelsell DP (2011) Harper's textbook of pediatric dermatology (3rd Edn), Collodion baby West Sussex, Blackwell Publishing, West Sussex, United Kingdom.

4. Van Gysel D, Lijnen RL, Moekti SS, de Laat PC, Oranje AP (2002) Collodion baby: a follow-up study of 17 cases. J Eur Acad Dermatol Venereol 16: 472-475.[Crossref]

5. Larregue M, Bressieux JM, Fournet JP (1976) Collodion baby. Mod Probl Paediatr 20: 40-49.[Crossref]

6. Harting M, Brunetti- Pierri N, Chen CS, Kirby J, Dishop MK, et al. (2008)Self-healing collodion membrane and mild nonbullous congenital ichthyosiform erythroderma due to 2 novel mutations in the ALOX12B gene. Arch Dermatol 144: 351-359.

7. Akcakus M, Gunes T, Kurtoglu S, Ozturk A (2003) Collodion baby associated with asymmetric crying facies: a case report. Pediatr Dermatol 20: 134-136.[Crossref]

8. Aradhya SS, Srinivas SM, Hiremagalore R, Shanmukappa AG (2013) Clinical outcome of collodion baby: a retrospective review. Indian J Dermatol Venereol Leprol 79: 553. [Crossref]

9. Rajpopat S, Moss C, Mellerio J, Vahlquist A, Gånemo A, et al. (2011) Harlequin ichthyosis: a review of clinical and molecular findings in 45 cases. Arch Dermatol 147: 681-686.[Crossref]

10. Elias PM, William ML, Jiang YJ, Schmuth M (2008) Pathogenesis of permeability barrier abnormalities in the ichthyoses: inherited disorders of lipid metabolism. J Lipid Res49: 697-714.

11. Conner JM, Soll RF, Edward Wh (2004) Topical ointment for preventing infection in preterm infants. Cochrane Database Syst Rev 1: CD001150.

12. Nopper AJ, Horii KA, Sookdeo-Drost S, Wang TH, Mancini AJ, et al. (1996) Topical ointment therapy benefits premature infants. J Pediatr 128: 660-669.[Crossref]

13. Taïeb A, Labrèze C (2002) Collodion baby: what's new. J Eur Acad Dermatol Venereol 16: 436-437.[Crossref]

14. Harvey HB, Shaw MG, Morrell DS (2010) Perinatal management of harlequin ichthyosis: a case report and literature review. J Perinatol 30: 66-72. [Crossref]

Copyright: (2017 Pandey R. This is an open-access article distributed under the terms of the Creative Commons Attribution License, which permits unrestricted use, distribution, and reproduction in any medium, provided the original author and source are credited. 